\title{
Are 3D Printing Templates an Advantage in Upper Thoracic Pedicle Screw Fixation?
}

Ismail Kaya ${ }^{1}$, İlker Deniz Cingöz ${ }^{1}$, Meryem Cansu Şahin ${ }^{2}$, Murat Atar ${ }^{3}$, Safak Ozyoruk ${ }^{4}$, Murat Sayin ${ }^{5}$, Nurullah Yuceer ${ }^{6}$

1. Neurosurgery, Usak University, Usak, TUR 2. Medical Physics, Kutahya Health Sciences University, Kutahya, TUR 3. Neurosurgery, Abdulhamid Han Research and Training Hospital, Istanbul, TUR 4. Neurosurgery, Private OFM Antalya Hospital, Antalya, TUR 5. Neurosurgery, Private Saglık Hospital, İzmir, TUR 6. Neurosurgery, İzmir Katip Çelebi University, İzmir, TUR

Corresponding author: Ismail Kaya, dr.ikaya85@gmail.com

\section{Abstract}

\section{Background}

This study aims to compare the clinical results of patients with upper thoracic vertebral fractures treated with pedicle screw and posterior spinal fusion with preoperative surgical planning and 3-dimensional (3D) modeling and patients treated with freehand screws.

\section{Methods}

Fifty patients who underwent pedicle screw placement with a diagnosis of upper thoracic fracture between June 2018 and October 2020 were included in our study. Pedicle screws were used in 25 patients (group 1) after the planning was completed with the help of 3D preoperative printing and modeling. Pedicle screws were applied in 25 patients in the control group (group 2) using the freehand technique. Intraoperative bleeding amount, operation time, and correct screw placement data in both groups were recorded.

\section{Results}

The operation time was $134 \pm 22$ minutes for group 1 and $152 \pm 38$ minutes for group 2 . The difference in operation times was found to be statistically significant $(p<0.05)$. Based on axial and sagittal reconstruction images, the accuracy rate of pedicle screw placement (grades 0 and 1 ) in group I was $96.6 \%$ compared to $83.6 \%$ in group II. The minor perforation rate (grade $1,<2 \mathrm{~mm}$ ) was $5.8 \%$ in group I compared to $11.8 \%$ in group II. The moderate perforation rate (grade $2,2-4 \mathrm{~mm}$ ) was $3.4 \%$ in group I compared to $14 \%$ in group II. The severe perforation rate (grade $3,>4 \mathrm{~mm}$ ) was $2.3 \%$ in group II; however, misplaced screws were not associated with neurological deficits. The difference in overall accuracy rates between the two groups was significant $(\mathrm{p}<0.05)$.

\section{Conclusions}

Review began 03/04/2021 Review ended 03/15/2021 Published 03/19/2021

\section{๑) Copyright 2021}

Kaya et al. This is an open access article distributed under the terms of the Creative Commons Attribution License CC-BY 4.0., which permits unrestricted use, distribution, and reproduction in any medium, provided the original author and source are credited.
For 3D models of upper thoracic pedicle screw insertion, guide plates can be produced inexpensively and individually. It provides a new method for the accurate placement of upper thoracic pedicle screws with high accuracy and secure use in screw insertion.

Categories: Neurosurgery
Keywords: 3d printing, pedicle screw, preoperative plan, upper thoracic trauma

\section{Introduction}

Spinal cord injuries are common in patients with upper thoracic vertebral fractures due to the smaller diameter of the spinal canal compared to the cervical and lumbar regions. Posterior screw fixation is applied in the upper thoracic region and is used in trauma, segmental instability, kyphosis, scoliosis, infection, and tumor treatments $[1,2]$. Pedicle screw fixation provides rigid intervertebral fixation but associated with complications, such as artery injury, nerve root damage, and dural damage [3, 4].

Advantages of surgical stabilization in upper thoracic vertebral injuries are correction of sagittal and coronal balance and neurological decompression in kyphotic fractures. Additionally, fixation and fusion prevent hyperkyphosis [5]. Anatomical studies indicate that thoracic pedicle screw insertion in the upper segments is more difficult than that in the lower segment due to the narrower diameter of the pedicles [6]. Moreover, the visualization of the upper thoracic region by X-ray and C-arm fluoroscopy during surgery is limited. This limitation of imaging in the preoperative period increases the risk of screw malposition. A number of studies reveal that inaccuracies in placement using these traditional techniques range from $10 \%$ to $50 \%$ [7]. In the authors' experience with image guidance in over 1500 cases, several potential pitfalls have been identified that could lead to sub-optimal results when using intraoperative spinal navigation [7]. 


\section{Cureus}

Currently, 3-dimensional printing technology is used in the preoperative evaluation of patients' anatomy, prosthesis, and implant applications. 3D printers help to increase surgical success by providing a preoperative simulation of surgical approaches [8, 9]. Models created with 3D compression are used in medical and surgical fields, such as cranial surgery, maxillofacial traumas, tissue engineering, chest deformities, and complex spine surgery $[8,10]$.

Creating patient-specific 3D printing models reduces complications during surgery by providing the surgeon with preoperative surgical planning and application. This study aims to compare the clinical results of patients with upper thoracic vertebral fractures treated with pedicle screw and posterior spinal fusion with preoperative surgical planning and 3D modeling and patients treated with freehand screws.

\section{Materials And Methods}

This article was previously posted to the Research Square preprint server on January 07,2021 . Patients diagnosed with upper thoracic fractures between June 2018 and October 2020 were evaluated according to Thoraco-Lumbar Injury Classification and Severity score (TLICS). Patients were deemed as appropriate candidates for spinal stabilization based on TLICS score of 5 or greater; patients suffering from upper thoracic trauma at T1-T6 segment accompanied with incomplete or complete spinal cord injury, and requiring surgery; patients with senile osteoporotic vertebral fracture and other upper thoracic trauma, not requiring surgery. The final diagnosis was based on the thoracic vertebral fracture and spinal cord injury in thoracic magnetic resonance imaging. Patients who had previously undergone spine surgery, preoperative radiation, chemotherapy, or had recurrent tumors and younger than 18 years were excluded from the study. Fifty patients with pedicle screw implantation were included in this study. Pedicle screws were applied in 25 patients (group I) after planning was completed with the help of 3D preoperative modeling. Pedicle screws were applied in 25 patients in the control group (group II) using the freehand technique. 3D printing was performed in the Kutahya Health Sciences University Research and Application Laboratory.

\section{Digital design and 3D printing}

Preoperative computed tomography (CT) images of 25 patients diagnosed with an upper thoracic fracture in the Neurosurgery Clinic were used for 3D models. Preoperative digital imaging and communications in medicine (DICOM) images of each patient were reconstructed using 32-channel computed tomography at a slice thickness of $0.625 \mathrm{~mm}$ and a planar resolution of $0.35 \mathrm{~mm}$ (Aquilion ${ }^{\mathrm{TM}}$ Large Bore CT, Canon Medical Systems, Tustin, USA) (Figure 1).
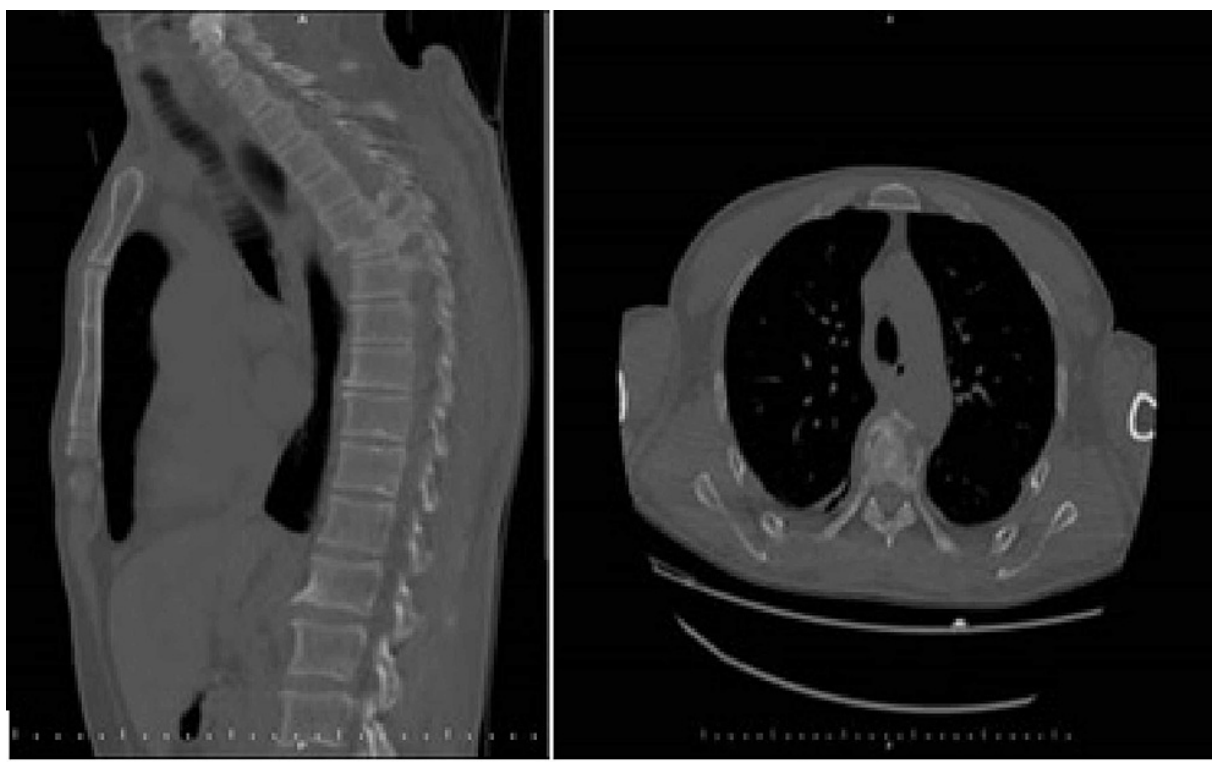

FIGURE 1: Preoperative CT view of the upper thoracic fracture.

CT images containing approximately 450 sections for each model were transferred to the 3D Slicer (version 4.10.1, Boston, MA, USA) program to create a 3D vertebral model. Using this software, the images were used to create 3D models of the vertebral region related to the complex surface treatment method. Whereas only the vertebral model was created from preoperative DICOM images (Figure 2). The templates to be used for pedicle screw placement were modeled in SolidWorks 2015 SP5 software (SolidWorks Corporation, Waltham, MA, USA) according to the measurements obtained from CT images and 3D vertebra models. 


\section{Cureus}

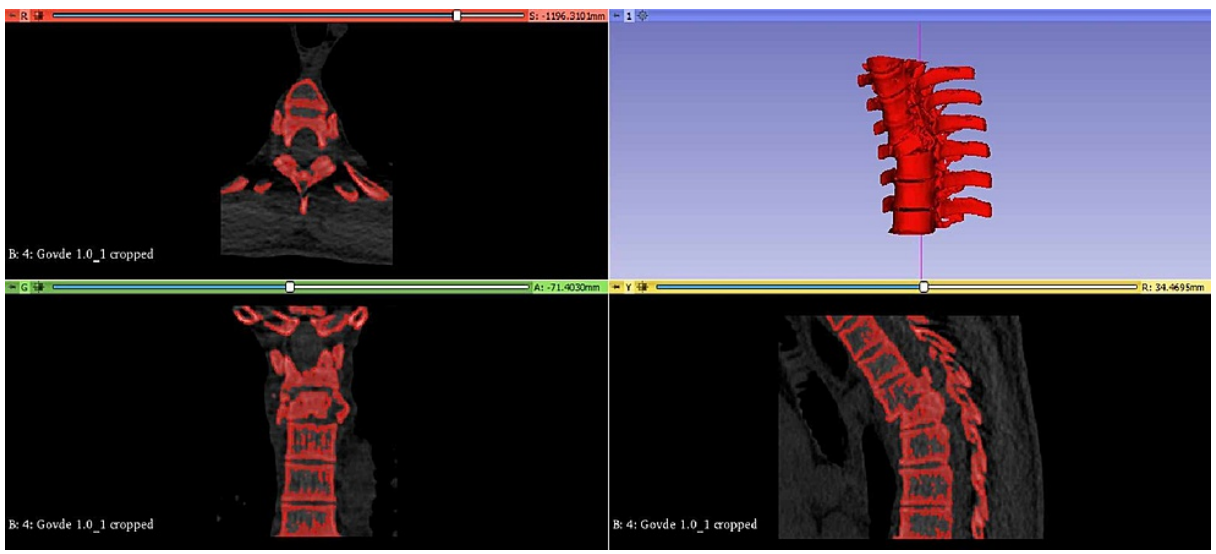

FIGURE 2: Modeling of the vertebrae in the 3DSlicer program.

3D vertebrae model and template data were saved in stereolithography (STL) format and transferred to Ultimaker Cura (version 4.7.1) (Ultimaker B.V., Utrecht, Netherlands) software. Printing parameters for preoperative vertebral models and templates were prepared in Ultimaker Cura software. The following printing parameters were used for Ultimaker 2 Extended 3D printer and polylactic acid (PLA) in Ultimaker Cura software for the printing of preoperative models: $0.4 \mathrm{~mm}$ nozzle diameter, $200^{\circ} \mathrm{C}$ nozzle temperature, $70^{\circ} \mathrm{C}$ build plate temperature, and $70 \%$ filling rate. Preoperative planning studies were performed on vertebra models and templates by the relevant surgeon (Figure 3).

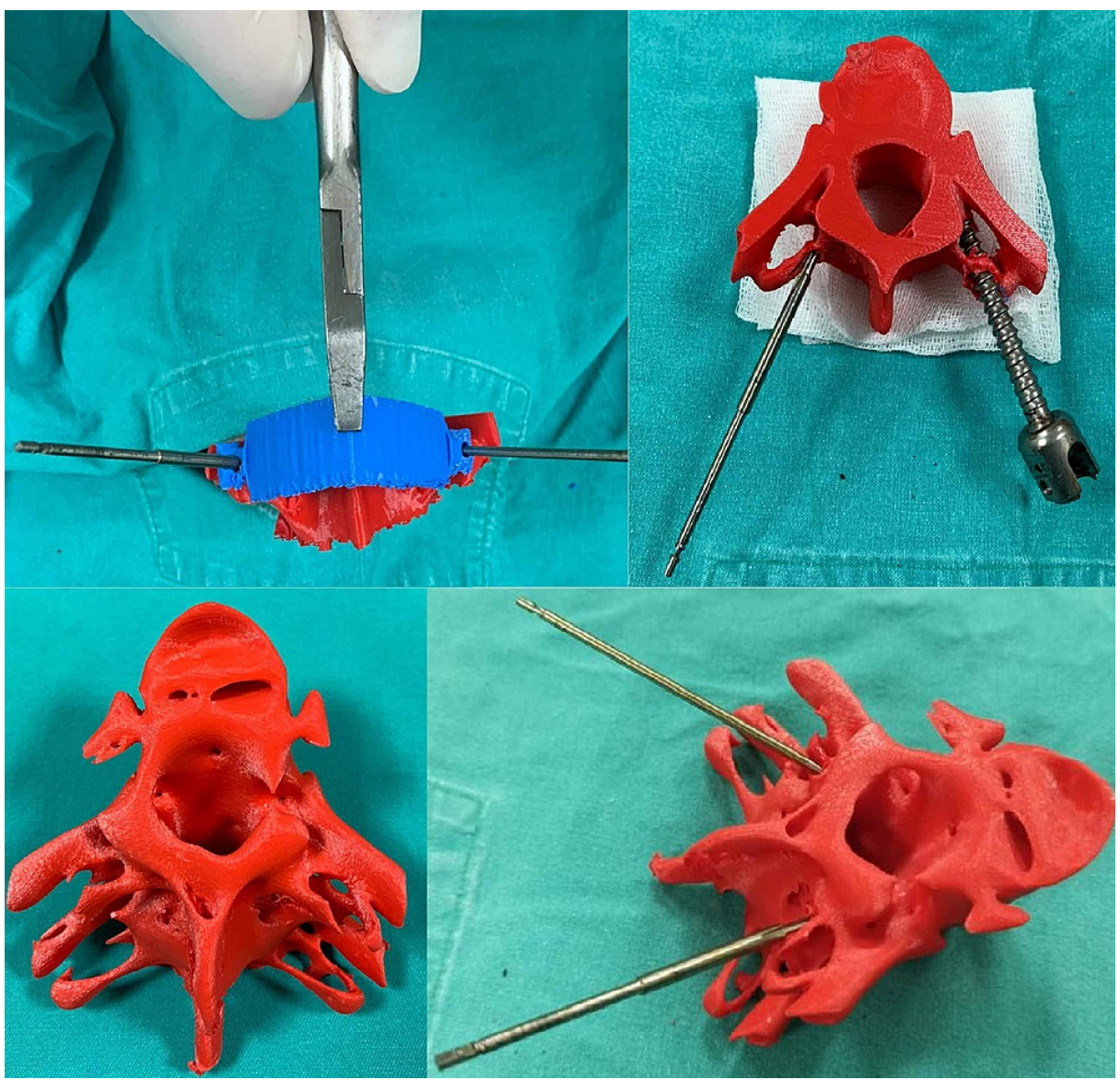

FIGURE 3: T4-T6 vertebrae prepared for preoperative planning.

\section{Operational methods}

Patients' operations were performed by the same surgeons. Preoperative modeling and planning of the patients to be operated on was done with the help of 3D printing and modeling methods. Patient-specific 


\section{Cureus}

full-scale spine models were available for reference at the time of surgery. Pedicle screws were placed from anatomic regions previously determined by planning and checked with fluoroscopy. In the control group patients, pedicle screws were placed using the freehand technique and under fluoroscopic control.

\section{Evaluation of efficacy}

Intraoperative bleeding amount, operation time, and correct screw placement data in both groups were recorded. Intraoperative bleeding was calculated by subtracting the volume of fluid used for flushing from the total fluid volume in the suction bag. The time of insertion of each pedicle screw was recorded.

A control CT scan was performed after the operation. Screw malpositions and violations of the medial and lateral walls of the pedicles were noted. The position of the screws was evaluated according to the Gertzbein classification [11]. In this classification, there are four categories for screw placement: grade 0 , screws are completely within the pedicle; grade 1 , perforation $<2 \mathrm{~mm}$; grade 2 , perforation between 2 and $4 \mathrm{~mm}$; and grade 3 , perforation $>4 \mathrm{~mm}$. In the current study, grades 0 and 1 were considered satisfactory, whereas grades 2 and 3 were regarded as perforated.

\section{Statistical analysis}

The statistical analysis was performed using SPSS 24.0 (IBM Corp., Armonk, NY, USA) software. Data are presented as the mean $\pm \mathrm{SD}\left(\mathrm{x}^{ \pm} \mathrm{S}\right)$, and intergroup comparisons were performed with independent-samples ttests. The enumeration data are expressed as a ratio, and intergroup comparisons were performed with the chi-square test; $\mathrm{p}=0.05$ was used as the statistical inspection standard.

\section{Results}

Of the 50 patients diagnosed with upper thoracic fractures, 25 were female, and 25 were male. The mean age of these 50 patients was $37.3 \pm 5.9$ years. No statistically significant difference was found between the groups in terms of age and gender (Table 1 ).

\begin{tabular}{|c|c|c|c|}
\hline & Group 1 & Group 2 & $p$-value ${ }^{\dagger}$ \\
\hline Number of Patients & 25 & 25 & - \\
\hline Sex & 14 Male /11 Female & 13 Male / 12 Female & 0.184 \\
\hline Age & $36.4 \pm 6.2$ & $38.1 \pm 5.7$ & 0.260 \\
\hline
\end{tabular}

\section{TABLE 1: Comparative demographic data of both groups.}

Based on axial and sagittal reconstruction images, the accuracy rate of pedicle screw placement (grades 0 and 1) in group I was $96.6 \%$ compared to $83.6 \%$ in group II (Table 2). The minor perforation rate (grade $1,<2$ $\mathrm{mm}$ ) was $5.8 \%$ in group I compared to $11.8 \%$ in group II. The moderate perforation rate (grade $2,2-4 \mathrm{~mm}$ ) was $3.4 \%$ in group I compared to $14 \%$ in group II. The severe perforation rate (grade $3,>4 \mathrm{~mm}$ ) was $2.3 \%$ in group II; however, misplaced screws were not associated with neurological deficits (Table 2). The difference in overall accuracy rates between the two groups was significant $(\mathrm{p}<0.05)$. 


\section{Cureus}

\begin{tabular}{|c|c|c|}
\hline Misplacement (according to Gertzbein's classification) & Group 1 ( $n=174$ screws) & Group 2 ( $n=171$ screws) \\
\hline Grade 0 (screws are completely within the pedicle) & $158(90.8 \%)$ & $123(71.9 \%)$ \\
\hline Grade 1 (screw perforation < 2 mm) & $10(5.8 \%)$ & $20(11.8 \%)$ \\
\hline Grade 2 (screw perforation between 2-4 mm) & $6(3.4 \%)$ & $24(14 \%)$ \\
\hline Grade 3 (screw perforation > 4 mm) & - & $4(2.3 \%)$ \\
\hline Accuracy $\dagger$ & $96.6 \%$ & $83.6 \%$ \\
\hline
\end{tabular}

\section{TABLE 2: Classification of patients according to Gertzbein scoring.}

† Accuracy $=($ grade $0+$ grade 1$) / \mathrm{n} \times 100 \%$

The operation time was $134 \pm 22$ minutes for group 1 and $152 \pm 38$ minutes for group 2 . The difference in operation times was found to be statistically significant $(\mathrm{p}<0.05)$ (Table 3$)$. The amount of blood loss for group 1 was $962 \pm 108 \mathrm{~mL}$. For group 2, it was $992 \pm 114 \mathrm{~mL}$. The difference in the amount of blood loss was not statistically significant $(\mathrm{p}>0.05$ ) (Table 3).

\begin{tabular}{|c|c|c|c|}
\hline & Group $1(n=25)$ & Group $2(n=25)$ & $p$-value ${ }^{\dagger}$ \\
\hline Operation Time (min) & $134 \pm 22$ & $152 \pm 38$ & $p<0.05$ \\
\hline Blood Loss (mL) & $962 \pm 108$ & $992 \pm 114$ & $p>0.05$ \\
\hline
\end{tabular}

\section{TABLE 3: Surgical data.}

† Compared with between group 1 and group 2

The mean TLICS scores for group 1 and group 2 were $6.3 \pm 4.2$ and $6.7 \pm 4.1$, respectively. Of the 25 upper thoracic fracture patients (group 1), five (20\%) were T3, eight (32\%) were T4, and 12 (48\%) were T6 fractures, which were operated on by 3D modeling with preoperative planning (Figures 4-6). For these 25 patients, the concordance rate between pedicle positions studied on preoperative models and postoperative pedicle screw positions was $93.8 \%$ for T3 fractures, $94.7 \%$ for T4 fractures, and $98.4 \%$ for T6 fractures (Table 4 ). 


\section{Cureus}

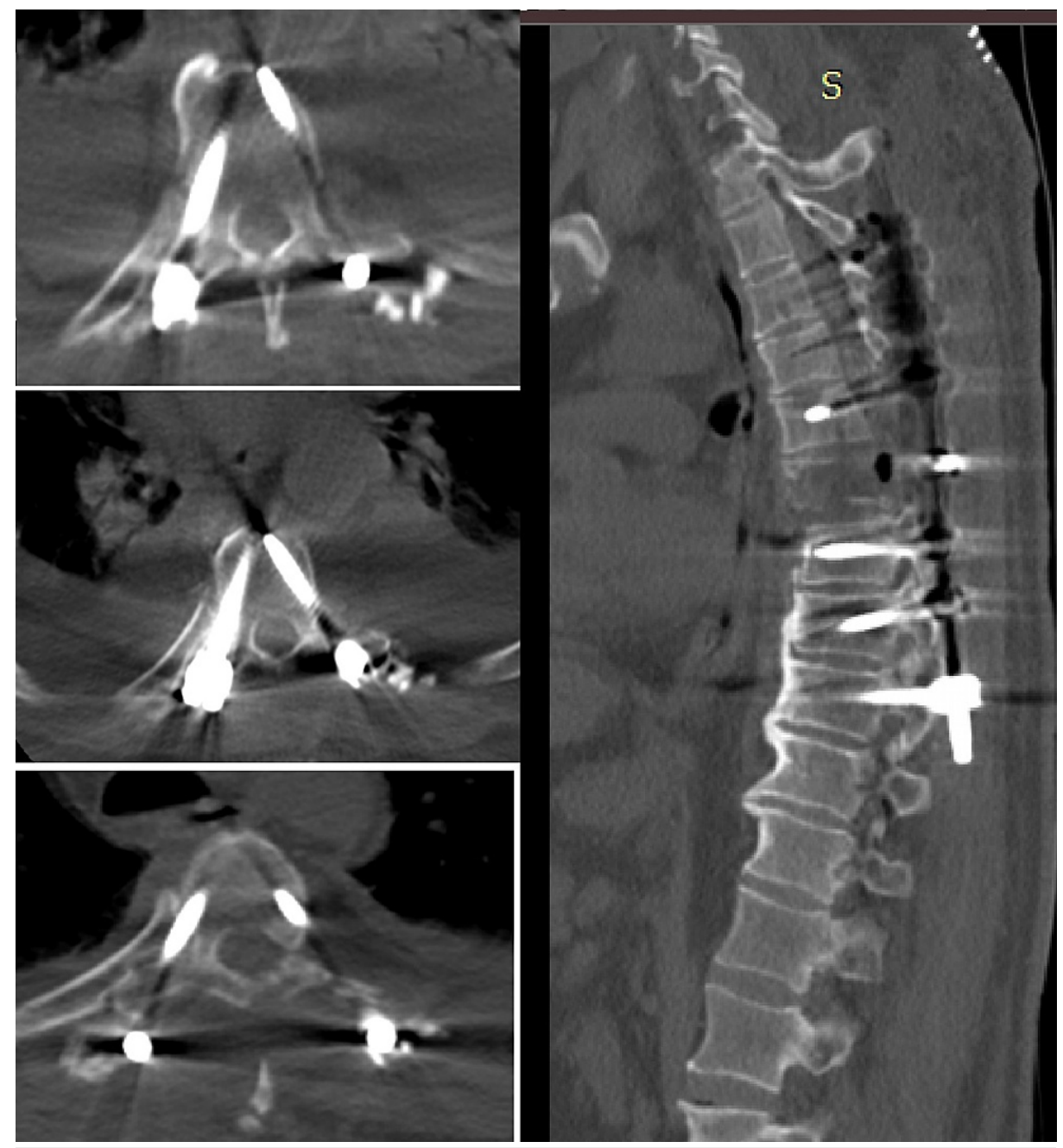

FIGURE 4: Postoperative CT image of a male patient operated with free hand technique. 


\section{Cureus}
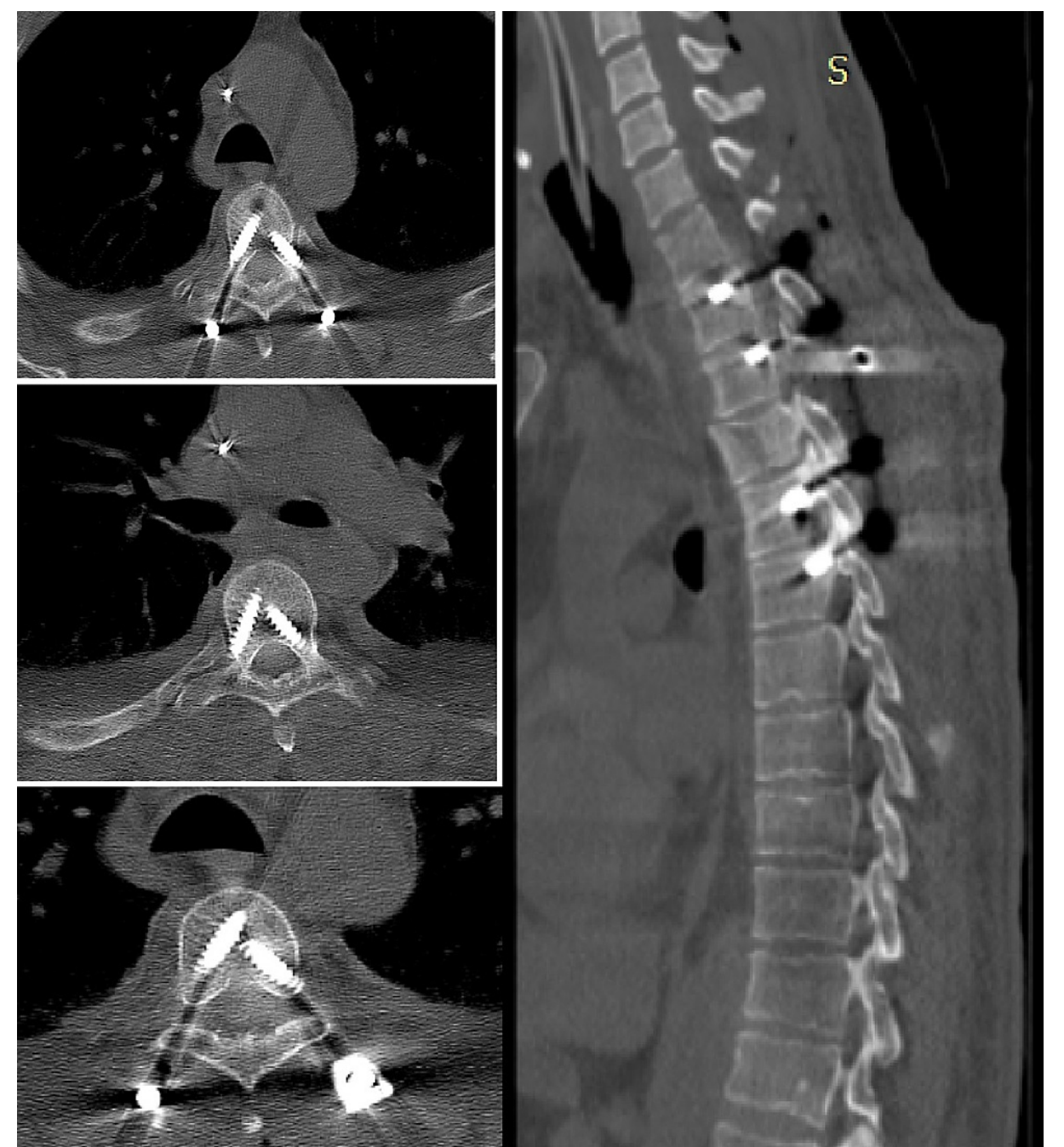

FIGURE 5: Postoperative CT image of a female patient operated with 3D modeling technique. 


\section{Cureus}
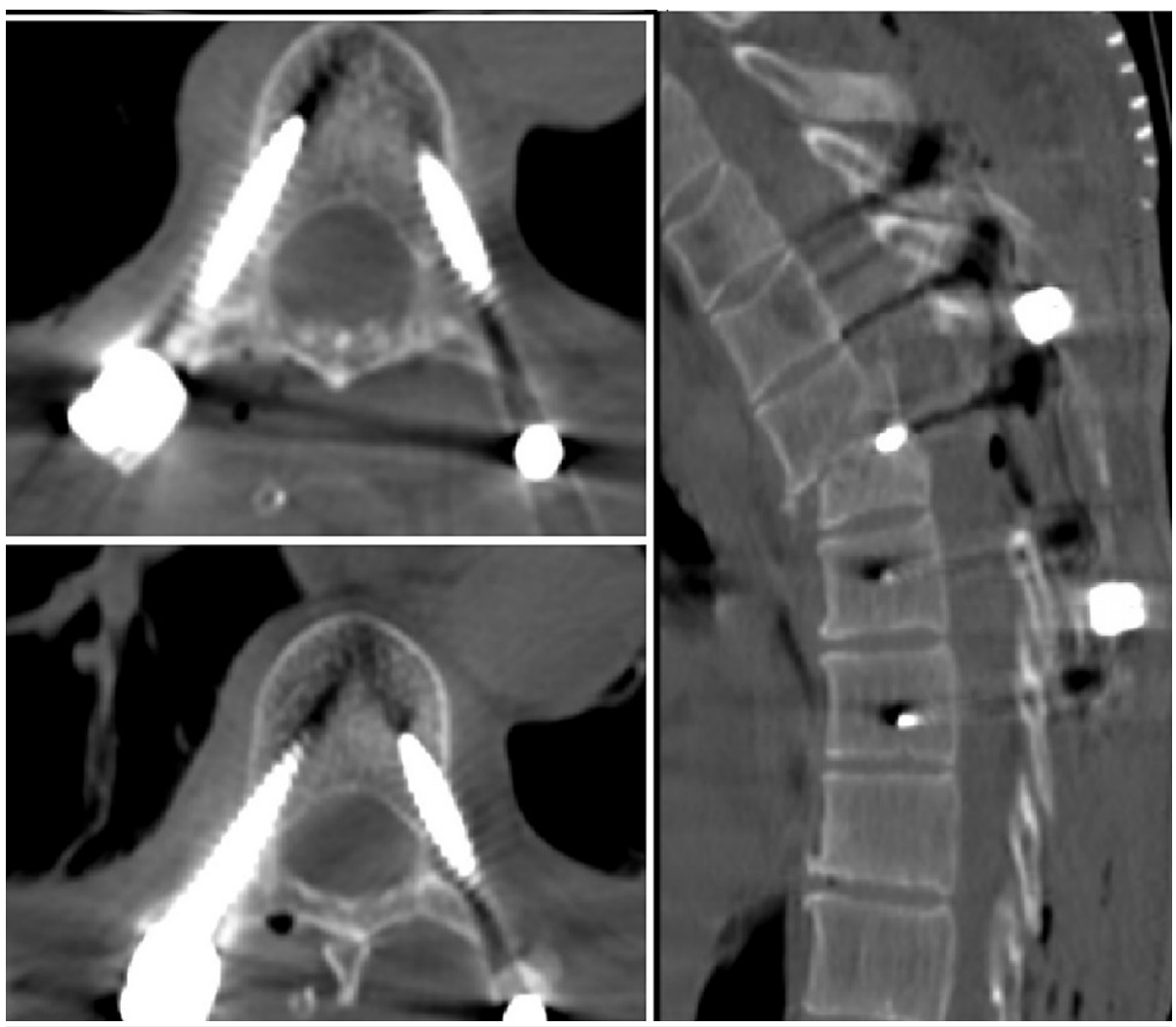

FIGURE 6: Postoperative CT image of a male patient operated with 3D modeling technique.

\begin{tabular}{|l|l|l|l|}
\hline Vertebral Model with Fracture Diagnosis & Pedicle Screw Size & Number of Pedicle Screws Inserted & Model Integrity Rate \\
\hline T3 & $4.0 \times 26 \mathrm{~mm}$ & 24 & $93.8 \%$ \\
T4 & $4.0 \times 26 \mathrm{~mm}$ & 57 & $94.7 \%$ \\
T6 & $6.0 \times 45 \mathrm{~mm}$ & 93 & $98.4 \%$ \\
\hline
\end{tabular}

\section{TABLE 4: Compliance of preoperative planning (Group 1) with postoperative pedicle screw} positions in the vertebral model.

The 3D printing time of vertebral templates produced for each patient was $14 \pm 3$ minutes. The amount of PLA used for the production of each template was $2 \pm 0.42$ grams. The total production cost of 25 templates produced for each patient was $\$ 5.31$.

\section{Discussion}

Upper and middle thoracic fractures are rare among spinal fractures. Approximately $10-20 \%$ of general spinal traumas are observed in this region [12]. Upper thoracic vertebral injuries often result in axial stress and bending with rotation and dislocation. This type of injury is generally seen at T4-T6 levels in motorcycle riders [13].

With the development of spine surgery, posterior thoracic interpedicular screwing has become more important. The key to this operation is the correct placement of the pedicle screw in one step, but it has been difficult due to safety concerns relating to the upper thoracic pedicle properties. The upper thoracic spine pedicles are smaller in diameter, and there are different angles for each spine. Thoracic pedicles are short and narrow, and their cortex is thin and fragile; therefore, thoracic pedicles are easily broken during screwing [14]. Additionally, the angles of the thoracic pedicles are different from each other, which has made the rate of error in placing thoracic pedicle screws at one time very high, causing serious consequences by damaging the surrounding tissues [15]. 
The anatomy of the thoracic pedicles is more complex, and screw insertion is more difficult in complex thoracic fractures and vertebral malformations. The penetration rate can reach $30-40 \%$ in the insertion of the thoracic pedicle screw with the freehand technique [16]. CT-based navigation systems are used to guide the placement of pedicle screws on the spine. Its use is not common due to its disadvantages, such as intraoperative position changes and spinal instability, lack of real-time navigation, and high cost [17].

With the use of 3D printing in spine surgeries, the production of guide plates, and provision of preoperative simulation, the accuracy of operations has increased. The fact that the accuracy is not affected by the intraoperative position and the higher reliability of guide plates provides superiority to navigation systems. Providing preoperative simulation and using the model as a guide during surgery reduce the surgeon's margin of error and operation time [18].

Controls performed with 2D fluoroscopy in upper thoracic interpedicular screwing show high error rates. Guzey et al. retrospectively examined 113 pedicle screws between T2-T8 in 24 patients without coronal deformity [19]. The control of the pedicle screws was checked during the operation by $\mathrm{C}$ arm fluoroscopy and postoperative CT. The faulty pedicle screw insertion rate was found to be $20.3 \%, 27.4 \%$ between $\mathrm{T} 2-\mathrm{T} 5$ and 14.5\% between T6-T8 [19]. Pedicular screws were applied to T4-T12 levels by five experienced surgeons on five fresh cadavers. In postoperative CTs, a faulty screw placement rate was found at a rate of approximately $41 \%$. Of these, 21 screws were observed to be in the vertebral canal by preparing the medial wall of the pedicle [4]. In our study, in patients who underwent surgery using the freehand technique, a total of 28 (16.3\%) incorrect pedicular screw placements were observed, 24 screws grade 2 (14\%) and four screws grade 3 (2.3\%).

With the application of 3D printing in spine surgeries, personalized production of guide plates, and preoperative simulation of the operation on the model have increased the accuracy of operations. Lu et al. used 3D modeling as an aid to cervical pedicle or vertebral plate screw placement and proved that it can provide correct placement of the screws [20]. Customized 3D spine models and screw insertion guide plates can be used to aid screw insertion and ensure the correct insertion of screws.

Mizutani et al. designed 3D models to apply cervical pedicle screws and achieved good results with guide plates in placing cervical pedicle screws [21]. Sugawara et al. created personal 3D navigation models for thoracic pedicle screws and applied pedicle screws under their guidance simply and safely. In 103 patients, 813 screws were placed with 3D guides. In postoperative CT scans, 801 screws (98.5\%) were placed without cortical violation, and no injury to the vessels and nerves was observed [9]. Xu et al. placed 56 pedicle screws in seven patients with upper and middle thoracic trauma using the 3D printing-supported preoperative plan method [10]. Regarding the placement of 56 screws according to postoperative CT images, 33 were grade 0 , 18 were grade 1 , four were grade 2 (perforated sidewall), and one was grade 3 (perforated sidewall, no vascular nerve injury). The accuracy rate was 91\% [22]. In our study, screw placement was performed according to postoperative CT images of 174 pedicle screws placed in the upper thoracic spine in 25 patients with preoperative 3D printing support and guidance, and $158(90.8 \%)$ were grade $0,10(5.8 \%)$ were grade 1 , and six (3.4\%) were grade 2 . Grade 3 positioning was not observed in any screw, and the pedicular screw placement accuracy rate was $96.6 \%$. Comparing the pedicle screw placement accuracy of the upper thoracic vertebrae (96.6\%) and the pedicle screw placement accuracy $(83.6 \%)$ of the freehand technique in the 3D printing-supported group, the difference was statistically significant $(\mathrm{p}<0.05)$.

In the study by Pan et al., 37 patients with spinal deformities were operated on, with group 1 (25 patients, 396 screws) supported by 3D printing and group 2 ( 25 patients, 312 screws) supported by the freehand method. The operation time in group 1 was $283 \pm 22.7$ minutes. In group 2 , it was $285 \pm 25.8$ minutes. The operation time was found to be shorter in group 1 , although the difference was not statistically significant (p $=0.89$ ) [23]. In our study, whereas the operation time was $134 \pm 22$ minutes for group 1 , it was $152 \pm 38$ minutes for group 2 . The difference in operation times was statistically significant $(\mathrm{p}<0.05)$.

In the study by Clifton et al., for 40 C7, 40 T6, and 40 L5 pedicle screws, the rate of agreement between the pedicle positions studied on preoperative models and the postoperative pedicle screw positions was found to be $100 \%$ for $\mathrm{C} 7,100 \%$ for T6, and $93 \%$ for L5 [24]. In our study, five (20\%) of the 25 upper thoracic fracture patients (group 1) were T3, eight (32\%) were T4, and 12 (48\%) were T6 fractures, which were operated on by preoperative planning using 3D modeling. For these 25 patients, the concordance rate between pedicle positions studied on preoperative models and postoperative pedicle screw positions was $93.8 \%$ for $\mathrm{T} 3$ fractures, $94.7 \%$ for T4 fractures, and $98.4 \%$ for T6 fractures.

Vertebral screw misplacement and vascular injuries are common in the upper thoracic region [25]. The ability to perform preoperative surgical simulation of the 3D printing-supported model, the application of the upper thoracic pedicle screw will become more efficient and easier. In our study, the accuracy rate obtained in the 3D printing-supported group was $96.5 \%$, which was higher than that of the freehand technique group. We think that the 3D printing-supported method in upper thoracic pedicle screw application will shorten learning time, provide easier learning on the model, and increase pedicular screw placement accuracy.

\section{Conclusions}


For upper thoracic pedicle screw insertion 3D models, guide plates can be produced inexpensively and individually. It provides a new method for accurate placement of upper thoracic pedicle screws with high accuracy and comfortable use in screw insertion.

\section{Additional Information \\ Disclosures}

Human subjects: Consent was obtained or waived by all participants in this study. Usak University Clinical Ethics Committee issued approval Not applicable. The study was approved by the Usak University Clinical Ethics Committee and was conducted following the Helsinki Declaration principles. Written informed consent was obtained from each patient after the study was described. Animal subjects: All authors have confirmed that this study did not involve animal subjects or tissue. Conflicts of interest: In compliance with the ICMJE uniform disclosure form, all authors declare the following: Payment/services info: All authors have declared that no financial support was received from any organization for the submitted work. Financial relationships: All authors have declared that they have no financial relationships at present or within the previous three years with any organizations that might have an interest in the submitted work. Other relationships: All authors have declared that there are no other relationships or activities that could appear to have influenced the submitted work.

\section{References}

1. Liljenqvist UR, Halm HF, Link TM: Pedicle screw instrumentation of the thoracic spine in idiopathic scoliosis. Spine. 1997, 22:2239-2245. 10.1097/00007632-199710010-00008

2. Abumi K, Kaneda K: Pedicle screw fixation for nontraumatic lesions of the cervical spine . Spine. 1997, 22:1853-1863. 10.1097/00007632-199708150-00010

3. Liljenqvist U, Hackenberg L, Link T, Halm H: Pullout strength of pedicle screws versus pedicle and laminar hooks in the thoracic spine. Acta Orthop Belg. 2001, 67:157-163.

4. Vaccaro AR, Rizzolo SJ, Balderston RA, Allardyce TJ, Garfin SR, Dolinskas C, An HS: Placement of pedicle screws in the thoracic spine. Part II: an anatomical and radiographic assessment. J Bone Joint Surg. 1995, 77:1200-1206. 10.2106/00004623-199508000-00009

5. Moon MS, Choi WT, Moon YW, Kim YS, Moon JL: Stabilisation of fractured thoracic and lumbar spine with Cotrel-Dubousset instrument. J Orthop Surg. 2003, 11:59-66. 10.1177/230949900301100113

6. Payer M: Unstable upper and middle thoracic fractures. Preliminary experience with a posterior transpedicular correction-fixation technique. J Clin Neurosci. 2005, 12:529-533. 10.1016/j.jocn.2004.11.006

7. Rahmathulla G, Nottmeier EW, Pirris SM, Deen HG, Pichelmann MA: Intraoperative image-guided spinal navigation: technical pitfalls and their avoidance. J Neurosurg Focus. 2014, 36:E3. 10.3171/2014.1.FOCUS13516

8. Vakharia VN, Vakharia NN, Hill CS: Review of 3-dimensional printing on cranial neurosurgery simulation training. World Neurosurg. 2016, 88:188-198. 10.1016/j.wneu.2015.12.031

9. Lador R, Regev G, Salame K, Khashan M, Lidar Z: Use of 3-dimensional printing technology in complex spine surgeries. World Neurosurg. 2020, 133:e327-e341. 10.1016/j.wneu.2019.09.002

10. Xu W, Zhang X, Ke T, Cai H, Gao X: 3D printing-assisted preoperative plan of pedicle screw placement for middle-upper thoracic trauma: a cohort study. BMC Musculoskelet Disord. 2017, 18:348. 10.1186/s12891017-1703-1

11. Gertzbein SD, Robbins S: Accuracy of pedicular screw placement in vivo . Spine. 1990, 15:11-14. 10.1097/00007632-199001000-00004

12. Hanley EN Jr, Eskay ML: Thoracic spine fractures. Orthopedics. 1989, 12:689-696.

13. Anthes TB, Muangman N, Bulger E, Stern EJ: Upper thoracic spine fracture dislocation in a motorcyclist . Curr Probl Diagn Radiol. 2012, 41:128-129. 10.1067/j.cpradiol.2011.07.009

14. Krag MH, Beynnon BD, Pope MH, Frymoyer JW, Haugh LD, Weaver DL: An internal fixator for posterior application to short segments of the thoracic, lumbar, or lumbosacral spine. Design and testing. Clin Orthop Relat Res. 1986, 75-98.

15. Lien SB, Liou NH, Wu SS: Analysis of anatomic morphometry of the pedicles and the safe zone for throughpedicle procedures in the thoracic and lumbar spine. Eur Spine J. 2007, 16:1215-1222. 10.1007/s00586-006$0245-2$

16. Kim YJ, Lenke LG, Bridwell KH, Cho Y, Riew KD: Free hand pedicle screw placement in the thoracic spine: is it safe?. Spine. 2004, 29:333-342. 10.1097/01.brs.0000109983.12113.9b

17. Gelalis ID, Paschos NK, Pakos EE, et al.: Accuracy of pedicle screw placement: a systematic review of prospective in vivo studies comparing free hand, fluoroscopy guidance and navigation techniques. Eur Spine J. 2012, 21:247-255. 10.1007/s00586-011-2011-3

18. Chen H, Guo K, Yang H, Wu D, Yuan F: Thoracic pedicle screw placement guide plate produced by threedimensional (3-D) laser printing. Med Sci Monit. 2016, 22:1682-1686. 10.12659/msm.896148

19. Guzey FK, Emel E, Hakan Seyithanoglu M, et al.: Accuracy of pedicle screw placement for upper and middle thoracic pathologies without coronal plane spinal deformity using conventional methods. J Spinal Disord Tech. 2006, 19:436-441. 10.1097/00024720-200608000-00011

20. Lu S, Xu YQ, Chen GP, et al.: Efficacy and accuracy of a novel rapid prototyping drill template for cervical pedicle screw placement. Comput Aided Surg. 2011, 16:240-248. 10.3109/10929088.2011.605173

21. Mizutani J, Matsubara T, Fukuoka M, et al.: Application of full-scale three-dimensional models in patients with rheumatoid cervical spine. Eur Spine J. 2008, 17:644-649. 10.1007/s00586-008-0611-3

22. Sugawara T, Higashiyama N, Kaneyama S, et al.: Multistep pedicle screw insertion procedure with patientspecific lamina fit-and-lock templates for the thoracic spine: clinical article. J Neurosurg Spine. 2013, 19:185-190. 10.3171/2013.4.SPINE121059 


\section{Cureus}

23. Pan Y, Lü GH, Kuang L, Wang B: Accuracy of thoracic pedicle screw placement in adolescent patients with severe spinal deformities: a retrospective study comparing drill guide template with free-hand technique. Eur Spine J. 2018, 27:319-326. 10.1007/s00586-017-5410-2

24. Clifton W, Pichelmann M, Vlasak A, Damon A, ReFaey K, Nottmeier E: Investigation and feasibility of combined 3D printed thermoplastic filament and polymeric foam to simulate the cortiocancellous interface of human vertebrae. Sci Rep. 2020, 10:2912. 10.1038/s41598-020-59993-2

25. Di Silvestre M, Parisini P, Lolli F, Bakaloudis G: Complications of thoracic pedicle screws in scoliosis treatment. Spine. 2007, 32:1655-1661. 10.1097/BRS.0b013e318074d604 